\title{
Promoting Effective Transitions of Care at Hospital Discharge: A Review of Key Issues for Hospitalists
}

\author{
Sunil Kripalani, MD, MSc ${ }^{1}$ \\ Amy T. Jackson, Pharmo ${ }^{2}$ \\ Jeffrey L. Schnipper, MD, MPH ${ }^{3}$ \\ Eric A. Coleman, $\mathrm{MD}, \mathrm{MPH}^{4}$ \\ ${ }^{1}$ Emory University School of Medicine, Atlanta, \\ Georgia \\ ${ }^{2}$ Emory Healthcare, Atlanta, Georgia \\ ${ }^{3}$ Brigham and Women's Hospital, Boston, Massa- \\ chusetts \\ ${ }^{4}$ University of Colorado Health Sciences Center, \\ Denver, Colorado
}

The authors thank Marra Katz for her editorial assistance in the preparation of this manuscript

Supported by NIH career development awards K23 HL077597 (to S.K.) and K08 HL072806 (to J.L.S), and a grant from the Paul Beeson Faculty Scholars in Aging Research/American Federation for Aging Research (to E.A.C.).

\begin{abstract}
The period following discharge from the hospital is a vulnerable time for patients. About half of adults experience a medical error after hospital discharge, and $19 \%-23 \%$ suffer an adverse event, most commonly an adverse drug event. This article reviews several important challenges to providing high-quality care as patients leave the hospital. These include the discontinuity between hospitalists and primary care physicians, changes to the medication regimen, new self-care responsibilities that may stress available resources, and complex discharge instructions. We also discuss approaches to promoting more effective transitions of care, including improvements in communication between inpatient and outpatient physicians, effective reconciliation of prescribed medication regimens, adequate education of patients about medication use, closer medical follow-up, engagement with social support systems, and greater clarity in physician-patient communication. By understanding the key challenges and adopting strategies to improve patient care in the transition from hospital to home, hospitalists could significantly reduce medical errors in the postdischarge period. Journal of Hospital Medicine 2007;2:314-323. (c) 2007 Society of Hospital Medicine.
\end{abstract}

KEYWORDS: continuity of care, hospital discharge, care transitions, medication reconciliation, physician-patient communication.

A s the counterpart to hospital admission, hospital discharge is a necessary process experienced by each living patient. For all patients except those being transferred to a continuing care facility, discharge is a period of transition from hospital to home that involves a transfer in responsibility from the inpatient provider or hospitalist to the patient and primary care physician (PCP). ${ }^{1}$ Prescription medications are commonly altered at this transition point, with patients asked to discontinue some medications, switch to a new dosage schedule of others, or begin new treatments. $^{2,3}$ Self-care responsibilities also increase in number and importance, presenting new challenges for patients and their families as they return home. ${ }^{4}$ Under these circumstances, ineffective planning and coordination of care can undermine patient satisfaction, facilitate adverse events, and contribute to more frequent hospital readmissions. ${ }^{5-8}$

Following hospital discharge nearly half $(49 \%)$ of hospitalized patients experience at least 1 medical error in medication continuity, diagnostic workup, or test follow-up. ${ }^{7}$ It has been reported that $19 \%-23 \%$ of patients suffer an adverse event, most frequently an adverse drug event (ADE). ${ }^{9-11}$ Half of ADEs are considered preventable or "ameliorable" (ie, their severity or duration could have been decreased). Most errors and adverse events in this 
setting result from a breakdown in communication between the hospital team and the patient or primary care physician. ${ }^{10}$

To promote more effective care transitions, The Joint Commission now requires accredited facilities to "accurately and completely reconcile medications across the continuum of care." 12 The Society of Hospital Medicine recently published recommendations for the discharge of elderly patients. ${ }^{13}$ The joint Society of Hospital Medicine-Society of General Internal Medicine Continuity of Care Task Force also recently published a systematic review with recommendations for improving the handoff of patient information at discharge. ${ }^{14}$ Apart from these reports, however, it is uncommon to find evidence-based recommendations for hospital discharge applicable to a broad range of patients. ${ }^{15}$ This review highlights several important challenges for physicians who seek to provide high-quality care during hospital discharge and the subsequent period of transition. Based on the best available evidence, recommendations are also provided for how to improve communication and facilitate the care transition for adult inpatients returning home.

\section{INPATIENT-OUTPATIENT PHYSICIAN DISCONTINUITY}

Traditionally, primary care physicians have admitted their own patients, provided hospital care (in addition to seeing outpatients during the day), and followed patients after discharge. Under this model, continuity of care has been preserved; however, this method of care has faltered under the weight of inpatients and outpatients with more severe illnesses, rapid technological advancements, managed care pressuring outpatient physicians to see more patients, and a thrust toward reduced hospital costs and length of stay. ${ }^{16}$ Increases in the efficiency and quality of hospital care have accompanied a new reliance on the field of hospital medicine, while allowing PCPs to focus on outpatient care. ${ }^{17-19}$ With more than 14,000 hospitalists currently practicing in the United States and 25,000 anticipated to be practicing by 2010, transfer of care from hospital-based providers to PCPs has become increasingly common at discharge. ${ }^{20}$

Patient discharge summaries are the most common means of communication between inpatient and outpatient providers. However, numerous studies have shown that discharge summaries often fail to provide important administrative and medical information, such as the primary diagnosis, results of abnormal diagnostics, details about the hospital course, follow-up plans, whether laboratory test results are pending, and patient or family counseling. ${ }^{14}$ Summaries also may not arrive in a timely manner and sometimes may not reach the PCP at all. ${ }^{21-23}$

At the time patients first follow up with their PCPs after hospitalization, discharge summaries have not yet arrived about $75 \%$ of the time, ${ }^{22,24,25}$ restricting the PCPs' ability to provide adequate follow-up care in $24 \%$ of hospital follow-up visits, according to one study. ${ }^{26}$ In another investigation, PCPs reported being unaware of $62 \%$ of the pending test results that returned after discharge, of which $37 \%$ were considered actionable. ${ }^{27}$

\section{Improving Physician Information Transfer and Continuity}

To improve information transfer from hospitalist to PCP, attention must be paid to the content, format, and timely delivery of discharge information (Table 1). ${ }^{14}$ Surveys of primary care physicians suggest the following information should be included in discharge summaries: diagnoses, abnormal physical findings, important test results, discharge medications, follow-up arrangements made and appointments that still need to be made, counseling provided to the patient and family, and tests still pending at discharge. ${ }^{2,28-33}$ These domains are consistent with Joint Commission guidelines for discharge summaries, ${ }^{34}$ and the inclusion of a detailed medication list and pending test results also has implications for patient safety. ${ }^{9-11,27}$

Because many patients follow up with their PCPs within a few days of discharge, it becomes important to provide the PCPs with some information about the hospitalization on the day of discharge. This can be accomplished via a quick telephone call, fax, or e-mail update to the PCP. ${ }^{24,35}$ Important things to include in this communiqué are the discharge diagnosis, medications, results of procedures, pending test results, follow-up arrangements, and suggested next steps. Within 1 week, a detailed discharge summary should have been received. ${ }^{26,33,36}$ As electronic medical records become more widely available, computer-generated summaries offer a way to more quickly and completely highlight the key elements of the hospitalization, and they are ready for delivery sooner than traditional dictated summaries. ${ }^{37}$ Additionally, all forms of discharge summaries-computer-generated, handwritten, and dictated-should include subheadings to better organize and present the in- 
TABLE 1

Recommendations for Improve Care Transitions at Hospital Discharge

\begin{tabular}{|c|c|}
\hline Challenge & Recommended approaches \\
\hline Inpatient-outpatient physician discontinuity & $\begin{array}{l}\text { When possible, involve the primary care physician (PCP) in discharge planning and work together to develop a } \\
\text { follow-up plan } \\
\text { At minimum, communicate the following to the PCP on the day of discharge: diagnoses, medications, results } \\
\text { of procedures, pending tests, follow-up arrangements, and suggested next steps } \\
\text { Provide the PCP with a detailed discharge summary within } 1 \text { week } \\
\text { In discharge summaries include: diagnoses, abnormal physical findings, important test results, discharge } \\
\text { medications with rationale for new or changed medications, follow-up arrangements made, counseling } \\
\text { provided to the patient and family, and tasks to be completed (eg, appointments that still need to be made } \\
\text { and tests that require follow-up) } \\
\text { Follow a structured template with subheadings in discharge communications } \\
\text { When possible, use health information technology to create and disseminate discharge summaries }\end{array}$ \\
\hline $\begin{array}{l}\text { Changes and discrepancies in medication } \\
\text { regimen }\end{array}$ & $\begin{array}{l}\text { Obtain a complete medication history by asking patients about: medications taken at different times of day; } \\
\text { medications prescribed by different physicians; nonoral medications; over-the-counter products; dosage, } \\
\text { indication, length of therapy, and timing of last dose of all drugs; allergies; and adherence } \\
\text { Compare and reconcile medication information obtained from patient and caregiver reports, patient lists, } \\
\text { prescription bottles, medical records, and pharmacy records } \\
\text { Display preadmission medication list prominently in the chart } \\
\text { Reconcile medications at all care transitions, including admission, intrahospital transfer, and discharge } \\
\text { Communicate complete and accurate medication information to the next provider at discharge, including } \\
\text { indications for new medications and reasons for any changes } \\
\text { When possible, partner with clinical pharmacists to manage medication information and reconciliation, } \\
\text { especially for high-risk patients }\end{array}$ \\
\hline Self-care responsibilities and social support & $\begin{array}{l}\text { Use multidisciplinary discharge planning teams to assess the needs of patients and their families } \\
\text { Arrange a specific follow-up appointment prior to discharge } \\
\text { Contact patients by telephone a few days after discharge to assess questions, symptoms, and medication- } \\
\quad \text { related issues } \\
\text { Order home health services when indicated } \\
\text { Consider home visits for frail elderly patients }\end{array}$ \\
\hline Ineffective physician-patient communication & $\begin{array}{l}\text { Focus discharge counseling on informing patients of major diagnoses, medication changes, dates of follow-up } \\
\text { appointments, self-care instructions, and who to contact if problems develop } \\
\text { Ensure that staff members communicate consistent instructions } \\
\text { For high-volume conditions, consider using audiovisual recordings for discharge education, combined with an } \\
\text { opportunity for additional counseling and questions } \\
\text { Use trained interpreters when a language gap exists } \\
\text { Provide simply written materials that include illustrations when possible to reinforce verbal instructions } \\
\text { Ensure patients and family members comprehend key points by asking them to teach back the information in } \\
\text { their own words and demonstrate any self-care behaviors } \\
\text { Encourage patients and family members to ask questions through an open-ended invitation like, "What } \\
\quad \text { questions do you have?" instead of "Do you have any questions?" }\end{array}$ \\
\hline
\end{tabular}

formation instead of unstructured narrative summaries. ${ }^{38}$

There is increasing interest in moving away from the traditional 1-way transfer of information about a hospitalization toward a 2-way dialogue between hospitalist and primary care physician. ${ }^{39}$ Preferences about how to do this will vary among physicians. One strategy might be to provide the PCP with the hospitalist's contact information and encouraging questions about the hospitalization. Another approach would involve contacting the PCP during the discharge planning process to exchange information about the patient, provide an opportunity for the PCP to ask questions about the hospitalization, and formulate a cohesive plan for follow-up, particularly about contingency planning (ie, what is most likely to go wrong and what should be done about it) and specific follow-up needs (ie, what tasks should be accomplished at the first postdischarge visit).

\section{CHANGES AND DISCREPANCIES IN THE MEDICATION REGIMEN}

Medication errors make up a large portion of the adverse events patients may experience in the period following hospital discharge. ${ }^{7}$ In fact, errors 
during the ordering of admission or discharge medications make up almost half of all hospital medication errors. ${ }^{40-43}$ At transition points such as admission and discharge, errors are often associated with changes in the medication regimen, including discrepancies between the new set of medication orders and what the patient was taking previously. In 2 recent studies, $54 \%$ of patients experienced at least 1 unintended medication discrepancy on admission to the hospital, and $39 \%-45 \%$ of these discrepancies were considered a potential threat to the patient. $^{44,45}$

At discharge, differences between the prescribed medication regimen and the prehospital regimen may exist for several reasons. First, physicians may not obtain a comprehensive and accurate medication history at the time of admission. ${ }^{46}$ The medication history elicited from the patient at hospital admission is often affected by health literacy, language barriers, current health status, medication-history interviewing skills, and time constraints. ${ }^{47}$ Physicians may not consult other important sources of medication information, including family members, prescription lists or bottles, and community pharmacy records. The most common error in the admission medication history is omitting a medication taken at home. ${ }^{46}$ Additionally, several providers, including a physician, a nurse, and an inpatient pharmacist, may independently take medication histories for the same patient. These multiple accounts lead to discrepancies that are rarely recognized or corrected.

Second, a patient's medication regimen can be significantly altered several times during a hospitalization. Acute illness may cause physicians to hold certain medications, discontinue others, or change prescribed doses during hospitalization. ${ }^{48}$ In addition, at most hospitals closed drug formularies necessitate automatic substitution of 1 medication for another drug in the same class during the patient's hospital stay. ${ }^{49}$ Changes from long-acting to shortacting medications are also routinely made in the name of tighter control (eg, of blood pressure). One study of hospitalized elders found that $40 \%$ of all admission medications had been discontinued by discharge and that $45 \%$ of all discharge medications were newly started during the hospitalization. ${ }^{3}$

Finally, at discharge, the current medication regimen needs to be reconciled with the preadmission medication regimen in a thoughtful manner. ${ }^{2}$ This includes resuming medications held or modified at admission for clinical reasons, resuming medications that were substituted in the hospital for formulary or pharmacokinetic reasons, and stopping newly started medications that were only required during the hospitalization (eg, for prevention of venous thromboembolism or stress ulcers). ${ }^{50}$ It is difficult, even in hospitals with advanced electronic health information systems, to prompt physicians to make these necessary changes. In a recent study, unexplained discrepancies between the preadmission medication list and discharge medication orders were noted in $49 \%$ of hospital discharges. ${ }^{51}$ Errors in discharge medication reconciliation may subsequently increase the risk of postdischarge ADEs. ${ }^{51}$

\section{Medication Reconciliation and Education}

An optimal strategy for obtaining a complete medication history may include asking patients about the following: a typical day and what medications are taken at different times of day; whether prescriptions come from more than 1 doctor; medications not taken orally (eg, inhalers, patches); dosages and indications for all medications; length of therapy and timing of last dose; over-the-counter products, herbals, vitamins, and supplements used and vaccinations received; allergies; and number of doses missed in the last week (Table 1). ${ }^{52-54}$ Forms are also available to help patients maintain a list of current medications. ${ }^{55-57}$

Ideally, the process of obtaining a medication history involves integration of information from several sources, including patient and caregiver recollections, patient-provided lists of medications, prescription bottles, outpatient medical records, and prescription refill information from community pharmacies. ${ }^{58,59}$ Any discrepancies in the information obtained should be explicitly resolved with the patient and/or caregiver. Assistance from a pharmacist or the patient's PCP may also be required.

Once the preadmission medication regimen is confirmed, it should be entered on a standardized form and placed in a prominent place in the chart. This list should then be compared against the patient's medication orders at admission, throughout the hospital stay, and at discharge. ${ }^{12}$ The planned action for each of these medications (eg, continue at same dose/route/frequency, substitute) should be made explicit. At discharge, this preadmission list also needs to be compared with the current hospital medications in order to create a coherent set of discharge orders. 
Staff responsibilities for obtaining and documenting an accurate list of preadmission medications and reconciling medications at admission, transfer, and discharge should be well defined and based on the resources available at each institution. Redundant work (eg, multiple personnel independently taking a medication history) should be replaced by interdisciplinary communication (ie, a member of the team confirming the accuracy of a list obtained by another member of the team). When discrepancies are found (eg, between preadmission and discharge medications), reconciliation requires correction of unintentional discrepancies and appropriate documentation of intentional changes. ${ }^{60}$

Because a patient's medications change frequently during the transitions of admission, intrahospital transfer, and discharge, reconciliation is an active and ongoing process that aims to ensure the patient is receiving the correct medication regimen at all times. Reconciliation also allows for a review of the safety and appropriateness of the regimen and discontinuation of any unsuitable or needless medications. ${ }^{61,62}$

Finally, a comprehensive list of a patient's medications should be reported to the next service provider when the patient is referred or transferred to another setting, service, practitioner, or level of care within or outside the organization. Avoiding overarching orders such as "continue home medications" and "resume all medications" becomes crucial to patient safety during transitions in care. At discharge, physicians should provide patients with a complete list of medications to be taken at home with indications and instructions for administration written in everyday language. Physicians should also highlight the results of medication reconciliation by pointing out any changes from the preadmission regimen, especially medications that are at home but should no longer be taken.

Ultimately, physicians have the duty to ensure that correct and complete medication information is provided. However, to achieve optimal results, physicians should partner with clinical pharmacists when possible. Pharmacists have been formally educated about and are experienced at taking medication histories, which may make them the ideal individuals to interview newly admitted patients about their medication histories. ${ }^{63}$ Unfortunately, according to a recent survey, pharmacists perform admission drug histories in only 5\% of U.S. hospitals and provide drug therapy counseling in just
$49 \%$ of U.S. hospitals. ${ }^{64}$ Patients who are elderly, have limited literacy skills, take more than 5 medications daily, or take high-risk medications such as insulin, warfarin, cardiovascular drugs (including antiarrhythmics), inhalers, antiseizure medications, eye medications, analgesics, oral hypoglycemics, oral methotrexate, and immunosuppressants may require additional counseling or pharmacist involvement for effective reconciliation. ${ }^{10,65,66}$

Although the evidence supporting medication reconciliation is limited, it is convincing enough to support carrying out such reconciliations. In 1 investigation, when the nursing staff obtained and pharmacists verified orders for home medications, the accuracy of admission medication orders increased from $40 \%$ to $95 \% .{ }^{67}$ In another work, in which there was pharmacist-led medication reconciliation, significant discrepancies were found in approximately $25 \%$ of patients' medication histories and admission orders. ${ }^{45}$ In the absence of pharmacist intervention, the authors predicted that $22 \%$ of the discrepancies could have caused some form of patient harm during hospitalization and that $59 \%$ of the discrepancies might have contributed to an adverse event if the error continued after discharge. ${ }^{45}$ Others report that orders were changed as a result of reconciliation for $94 \%$ of patients being transferred out of the intensive care unit. ${ }^{2}$ Finally, in a randomized controlled trial of a pharmacist intervention at discharge in which medication reconciliation was the most common action performed, after 30 days preventable ADEs were detected in $11 \%$ of control patients and $1 \%$ of intervention patients. Medication discrepancy was the cause of half the preventable ADEs in the control group. ${ }^{51}$

\section{SELF-CARE RESPONSIBILITIES AND SOCIAL SUPPORT}

Compounding the difficulties at discharge are the economic pressures on our health care system, causing patients to be released from the hospital "quicker and sicker" than ever before. ${ }^{68}$ The scope of care provided to patients also undergoes a major shift at discharge. Multidisciplinary providers no longer continually review the health status and needs of patients; instead, patients must follow up with their outpatient physician over a period of days to weeks. In the interim, the patients themselves are responsible for administering new medications, participating in physical therapy, and tracking their own symptoms to see if they are 
worsening. For many patients, sufficient social and family support is not available to help perform these activities effectively. Unfortunately, hospital personnel often inaccurately assess patients' functional status and overestimate patients' knowledge of required self-care activities. ${ }^{69}$

\section{Providing Adequate Medical and Social Support}

A multidisciplinary discharge planning team can facilitate proper assessments of the social needs of patients and their families (Table 1) ${ }^{70-72}$ This team is often composed of a nurse case manager and a social worker but may also include a physical therapist, an occupational therapist, a pharmacist, and other health care providers. Following discussion with a patient and the patient's family, the team may suggest home health services during the transition home to supplement available medical support, ${ }^{73}$ or they may decide that discharge to a rehabilitation or skilled nursing facility is more appropriate.

In addition, follow-up should be arranged prior to discharge. Patients who are given a set appointment are more likely to show up for their follow-up visits than are those who are simply asked to call and arrange their own visits. ${ }^{74}$ Typically, follow-up with the PCP should be conducted within 2 weeks of hospital discharge. However, depending on a patient's functional status, pending test results, and need for medication monitoring or follow-up testing, this may need to take place sooner. Interestingly, research indicates that follow-up appointments with the inpatient provider can result in a lower combined rate of readmission and 30-day mortality. ${ }^{75}$ Thus, hospitalists may consider operating a hospitalist-staffed follow-up clinic, especially for patients without a regular PCP.

Telephone follow-up conducted a few days after discharge can also be an effective means of bridging the inpatient-outpatient transition. ${ }^{35}$ Such follow-up provides a chance to attend to any patient questions, new or concerning symptoms, and medication-related issues (eg, not filling the discharge medications or difficulty comprehending the new medication regimen). ${ }^{76} \mathrm{~A}$ physician, physician assistant, advanced practice nurse, registered nurse, pharmacist, or care manager can effectively carry out this telephone follow-up. No matter who telephones, the caller must be aware of the patient's recent course of events as well as the care plan decided at discharge. Published evidence indicates that telephone follow-up fosters patient sat- isfaction, increases medication adherence, decreases preventable ADEs, and decreases the number of subsequent emergency room visits and hospital readmissions, ${ }^{51,77,78}$ although not all evaluations have demonstrated benefit. ${ }^{79}$ As with medication histories performed by pharmacists, limited resources may mean that such follow-up be restricted to those patients at highest risk for readmission.

Home visits may be appropriate for certain patient populations, such as the frail elderly. ${ }^{80}$ Home visits enable a patient's daily needs and safety (eg, fall risk) to be assessed. They can also be a means of assessing medication safety and adherence by reviewing all prescription and over-the-counter products in the household. ${ }^{81}$ Close follow-up of at-risk or elderly patients after discharge can help to minimize hospital readmission and total health care costs. ${ }^{4,82-85}$

\section{INEFFECTIVE PHYSICIAN-PATIENT COMMUNICATION}

Physician-patient communication is fundamental to the practice of medicine and is crucially important at discharge. However, several studies have demonstrated a disconnect between physician information giving and patient understanding. ${ }^{76,96-90}$ When providing instructions, physicians commonly use medical jargon and attempt to cover a wealth of information in a limited amount of time. ${ }^{69,87}$ They also tend to rely on verbal instructions and fail to provide supplementary audiovisual materials (eg, educational handouts or videos) that could aid patient comprehension. Physicians may not point out important self-care tasks that patients should carry out at home. The entire interaction may be rushed or seem rushed. Moreover, when physicians solicit questions from patients, they may only allow for yes/no responses by using statements like "Any questions?" or "Do you have any questions?" that make it easy for patients to simply respond, "No." The encounter usually comes to an end without true confirmation of a patient's level of understanding or assessment of a patient's ability to perform the self-care activities and medication management required on returning home. ${ }^{81}$

Adding to the challenges of effective physicianpatient communication is the large number of adult Americans (more than 90 million) who have limited functional literacy skills. ${ }^{91,92}$ Such patients typically have difficulty reading and understanding medical instructions, medication labels, and appointment slips. ${ }^{93-96}$ Not surprisingly, patients with limited lit- 
eracy skills know less about their chronic illnesses and how to manage their diseases. ${ }^{97}$ Having low literacy is also linked to increased use of emergency department services, a higher risk of hospitalization, and higher health care costs. ${ }^{97-99}$ Patients with limited English proficiency have similar or even greater challenges and also have longer stays in the hospital. ${ }^{100}$

\section{More Effective Physician-Patient Communication}

Discharge counseling should concentrate on the few key points that are of the greatest interest and the most importance to patients: major diagnoses, medication changes, dates of follow-up appointments, self-care instructions, and who to contact if problems develop (Table 1). ${ }^{101}$ Furthermore, these key instructions should be reinforced by other hospital staff, including nurses and pharmacists. For common conditions (eg, high-volume cardiac procedures), offering standardized audiovisual instructions can be both efficient and worthwhile if used in conjunction with question-answer sessions. ${ }^{102}$ In the event that physicians and hospital staff cannot fluently communicate in a patient's language, it is essential to engage trained interpreters, not rely on rudimentary language skills, the patient's family, or other ad hoc ways to communicate. ${ }^{103}$

Because patients are unlikely to fully remember verbal instructions at discharge, it is helpful to provide patients and family members with written materials to take home in order to reinforce important self-care instructions. ${ }^{76,87}$ These materials, written at a 5th- to 8th-grade reading level, should outline key information in a simple format with little or no medical jargon. Illustrated materials are often better comprehended and subsequently remembered by patients. ${ }^{104,105}$ If preprinted illustrated materials are not on hand, then physicians can convey key points by drawing simple pictures.

Confirming patient comprehension with the "teach-back" method is perhaps the most important step in effectively communicating discharge instructions. $^{106}$ With this method, patients are asked to repeat back what they understand from the discharge instructions. Application of this simple technique is advocated as one of the most effective means of improving patient safety. ${ }^{107,108} \mathrm{~Pa}-$ tients should also be asked to demonstrate any new self-care tasks that they will be required to carry out at home, such as using an inhaler or administering a subcutaneous injection.

Last, The Joint Commission recently created a
National Patent Safety Goal to "encourage the active involvement of patients and their families in the patient's own care." ${ }^{12}$ This charge requires that physicians offer ample time for patients and their family members to ask questions. Physicians should avoid questions with yes/no responses and instead invite patient and family member questions in a more open-ended manner (eg, "What questions do you have?") to help ensure comprehension and comfort with the care plan.

\section{CONCLUSIONS}

The transition from hospital to home is a vulnerable period of discontinuity and potential adverse events. Hospitalists and other inpatient providers should not view discharge as an end to their obligation to patients but rather should attempt to promote a safe and efficient transition of care. Hospitalists can play an important role in bridging the gap between inpatient and outpatient care through appropriate discharge planning and effective communication with patients, their family members, and outpatient physicians.

Address for correspondence and reprint requests: Sunil Kripalani, MD, MSc, Assistant Professor, Emory University School of Medicine, 49 Jesse Hill Jr. Dr. SE, Atlanta, GA 30303; Fax: (404) 778-1602; E-mail: skripal@emory.edu

Received 3 January 2007; revision received 23 March 2007; accepted 1 April 2007

\section{REFERENCES}

1. Manian FA. Whither continuity of care? $N$ Engl J Med. 1999;340:1362-1363.

2. Pronovost P, Weast B, Schwarz M, et al. Medication reconciliation: a practical tool to reduce the risk of medication errors. J Crit Care. 2003;18(4):201-205.

3. Beers MH, Dang J, Hasegawa J, Tamai IY. Influence of hospitalization on drug therapy in the elderly. J Am Geriatr Soc. 1989;37:679-683.

4. Coleman EA, Smith JD, Frank JC, Min SJ, Parry C, Kramer AM. Preparing patients and caregivers to participate in care delivered across settings: the Care Transitions Intervention. J Am Geriatr Soc. 2004;52:1817-1825.

5. Bull MJ, Hansen HE, Gross CR. Predictors of elder and family caregiver satisfaction with discharge planning. J Cardiovasc Nurs. 2000;14(3):76-87.

6. Clare J, Hofmeyer A. Discharge planning and continuity of care for aged people: indicators of satisfaction and implications for practice. Aust J Adv Nurs. 1998;16(1):7-13.

7. Moore C, Wisnivesky J, Williams S, McGinn T. Medical errors related to discontinuity of care from an inpatient to an outpatient setting. J Gen Intern Med. 2003;18:646-651.

8. Coleman EA, Mahoney E, Parry C. Assessing the quality of preparation for posthospital care from the patient's perspective: the care transitions measure. Med Care. 2005; 43(3):246-255. 
9. Forster AJ, Clark HD, Menard A, et al. Adverse events among medical patients after discharge from hospital. CMAJ. 2004;170:345-349.

10. Forster AJ, Murff HJ, Peterson JF, Gandhi TK, Bates DW. The incidence and severity of adverse events affecting patients after discharge from the hospital. Ann Intern Med. 2003;138:161-167.

11. Forster AJ, Murff HJ, Peterson JF, Gandhi TK, Bates DW. Adverse drug events occurring following hospital discharge. J Gen Intern Med. 2005;20:317-323.

12. The Joint Commission. Joint Commission National Patient Safety Goals. Available at: http://www.jointcommission. org/PatientSafety/NationalPatientSafetyGoals/. Accessed July 17, 2006.

13. Halasyamani L, Kripalani S, Coleman EA, et al. Transition of care for hospitalized elderly patients - Development of a discharge checklist for hospitalists. J Hosp Med. 2006;1:354360 .

14. Kripalani S, LeFevre F, Phillips CO, Williams MV, Basaviah P, Baker DW. Deficits in communication and information transfer between hospital-based and primary care physicians: implications for patient safety and continuity of care. JAMA. 2007;297:831-841.

15. Agency for Healthcare Research and Quality. National Guideline Clearinghouse. Available at: http://www.guideline. gov. Accessed January 3, 2007.

16. Wachter RM, Goldman L. The emerging role of "hospitalists" in the American health care system. $N$ Engl J Med. 1996;335:514-517.

17. Wachter RM. Hospitalists in the United States-mission accomplished or work in progress? N Engl J Med. 2004;350: 1935-1936.

18. Wachter RM. The evolution of the hospitalist model in the United States. Med Clin North Am 2002;86(4):687-706.

19. Wachter RM, Goldman L. The hospitalist movement 5 years later. JAMA. 2002;287:487-494.

20. Society of Hospital Medicine. Growth of hospital medicine nationwide. Available at: http://www.hospitalmedicine. org/Content/NavigationMenu/Media/GrowthofHospitalMedicineNationwide/Growth_of_Hospital_M.htm. Accessed July 17, 2006.

21. Bertrand D, Francois P, Bosson JL, Fauconnier J, Weil G. Quality assessment of discharge letters in a French university hospital. Int J Health Care Qual Assur Inc Leadersh Health Serv. 1998;11(2-3):90-95.

22. van Walraven C, Seth R, Laupacis A. Dissemination of discharge summaries. Not reaching follow-up physicians. Can Fam Physician. 2002;48:737-742.

23. van Walraven C, Weinberg AL. Quality assessment of a discharge summary system. CMAJ. 1995;152:1437-1442.

24. Pantilat SZ, Lindenauer PK, Katz PP, Wachter RM. Primary care physician attitudes regarding communication with hospitalists. Am J Med. 2001;111(9B):15S-20S.

25. van Walraven C, Seth R, Austin PC, Laupacis A. Effect of discharge summary availability during post-discharge visits on hospital readmission. J Gen Intern Med. 2002;17(3): 186-192.

26. Harding J. Study of discharge communications from hospital doctors to an inner London general practice. J R Coll Gen Pract. 1987;37:494-495.

27. Roy CL, Poon EG, Karson AS, et al. Patient safety concerns arising from test results that return after hospital discharge. Ann Intern Med. 2005;143(2):121-128.

28. Newton J, Eccles M, Hutchinson A. Communication between general practitioners and consultants: what should their letters contain? BMJ 1992;304(6830):821-824.

29. Stalhammar J, Holmberg L, Svardsudd K, Tibblin G. Written communication from specialists to general practitioners in cancer care. What are the expectations and how are they met? Scand J Prim Health Care. 1998;16(3):154-159.

30. Balla JI, Jamieson WE. Improving the continuity of care between general practitioners and public hospitals. Med J Aust. 1994;161:656-659.

31. King MH, Barber SG. Towards better discharge summaries: brevity and structure. West Engl Med J. 1991;106(2):40-41, 55 .

32. Solomon JK, Maxwell RB, Hopkins AP. Content of a discharge summary from a medical ward: views of general practitioners and hospital doctors. JR Coll Physicians Lond. 1995;29:307-310.

33. van Walraven C, Rokosh E. What is necessary for highquality discharge summaries? Am J Med Qual. 1999;14(4): 160-169.

34. The Joint Commission. Standard IM.6.10. Hospital Accreditation Standards. Oakbrook Terrace, IL: The Joint Commission; 2006:338-340.

35. Nelson JR. The importance of postdischarge telephone follow-up for hospitalists: a view from the trenches. Am J Med. 2001;111(9B):43S-44S.

36. Bolton P, Mira M, Kennedy P, Lahra MM. The quality of communication between hospitals and general practitioners: an assessment. J Qual Clin Pract. 1998;18:241-247.

37. van Walraven C, Laupacis A, Seth R, Wells G. Dictated versus database-generated discharge summaries: a randomized clinical trial. CMAJ. 1999;160:319-326.

38. van Walraven C, Duke SM, Weinberg AL, Wells PS. Standardized or narrative discharge summaries. Which do family physicians prefer? Can Fam Physician. 1998;44:62-69.

39. Lee RG, Garvin T. Moving from information transfer to information exchange in health and health care. Soc Sci Med. 2003;56:449-464.

40. Bates DW, Spell N, Cullen DJ, et al. The costs of adverse drug events in hospitalized patients. Adverse Drug Events Prevention Study Group. JAMA. 1997;277:307-311.

41. Leape LL, Bates DW, Cullen DJ, et al. Systems analysis of adverse drug events. ADE Prevention Study Group. JAMA. 1995;274(1):35-43.

42. Bates DW, Cullen DJ, Laird N, et al. Incidence of adverse drug events and potential adverse drug events. Implications for prevention. ADE Prevention Study Group. JAMA. 1995;274(1):29-34.

43. LaPointe NM, Jollis JG. Medication errors in hospitalized cardiovascular patients. Arch Intern Med. 2003;163:14611466.

44. Cornish PL, Knowles SR, Marchesano R, et al. Unintended medication discrepancies at the time of hospital admission. Arch Intern Med. 2005;165:424-429.

45. Gleason KM, Groszek JM, Sullivan C, Rooney D, Barnard C, Noskin GA. Reconciliation of discrepancies in medication histories and admission orders of newly hospitalized patients. Am J Health Syst Pharm. 2004;61:1689-1695. 
46. Tam VC, Knowles SR, Cornish PL, Fine N, Marchesano R, Etchells EE. Frequency, type and clinical importance of medication history errors at admission to hospital: a systematic review. CMAJ. 2005;173:510-515.

47. Sullivan C, Gleason KM, Rooney D, Groszek JM, Barnard C. Medication reconciliation in the acute care setting: opportunity and challenge for nursing. J Nurs Care Qual. 2005; 20(2):95-98.

48. Omori DM, Potyk RP, Kroenke K. The adverse effects of hospitalization on drug regimens. Arch Intern Med. 1991; 151:1562-1564.

49. Schachtner JM, Guharoy R, Medicis JJ, Newman N, Speizer R. Prevalence and cost savings of therapeutic interchange among U.S. hospitals. Am J Health Syst Pharm. 2002;59: 529-533.

50. Holzmueller CG, Hobson D, Berenholtz SM, et al. Medication reconciliation: are we meeting the requirements? JCOM. 2006;13:441-444.

51. Schnipper JL, Kirwin JL, Cotugno MC, et al. Role of pharmacist counseling in preventing adverse drug events after hospitalization. Arch Intern Med. 2006;166:565-571.

52. Nester TM, Hale LS. Effectiveness of a pharmacist-acquired medication history in promoting patient safety. Am J Health Syst Pharm. 2002;59:2221-2225.

53. Jacobson J. Ensuring continuity of care and accuracy of patients' medication history on hospital admission. Am J Health Syst Pharm. 2002;59:1054-1055.

54. Ellington AE, Barnett CW, Johnson DR, Nykamp D. Current methods used to teach the medication history interview to doctor of pharmacy students. Am J Pharm Educ. 2002; 66(Summer):103-107.

55. AARP. My Personal Medication Record. Available at: http:// assets.aarp.org/www.aarp.org_/articles/learntech/wellbeing/ medication-record.pdf. Accessed October 20, 2006.

56. AARP. Mi registro de medicacion. Available at: http:// assets.aarp.org/www.aarp.org_/articles/health/docs/ PersonalMedRecordSP.pdf. Accessed October 20, 2006.

57. Institute for Safe Medication Practices. Available at: http:// www.ismp.org. Accessed September 8, 2006.

58. Porter SC, Kohane IS, Goldmann DA. Parents as partners in obtaining the medication history. J Am Med Inform Assoc. 2005;12:299-305.

59. Andersen SE, Pedersen AB, Bach KF. Medication history on internal medicine wards: assessment of extra information collected from second drug interviews and GP lists. Pharmacoepidemiology Drug Saf. 2003;12:491-498.

60. Medication Discrepancy Tool. Available at: http://www. caretransitions.org. Accessed July 28, 2005.

61. Fick DM, Cooper JW, Wade WE, Waller JL, Maclean JR, Beers MH. Updating the Beers criteria for potentially inappropriate medication use in older adults: results of a US consensus panel of experts. Arch Intern Med. 2003;163: 2716-2724.

62. Lewis T. Using the NO TEARS tool for medication review. BMJ 2004;329(7463):434.

63. Kaboli PJ, Hoth AB, McClimon BJ, Schnipper JL. Clinical pharmacists and inpatient medical care: a systematic review. Arch Intern Med. 2006;166:955-964.

64. Bond CA, Raehl CL. Clinical pharmacy services, pharmacy staffing, and adverse drug reactions in United States hospitals. Pharmacotherapy. 2006;26:735-747.
65. Gandhi TK, Weingart SN, Borus J, et al. Adverse drug events in ambulatory care. $N$ Engl J Med. 2003;348:1556-1564.

66. MA Coalition for the Prevention of Medical Errors. Reconciling medications. Recommended practices. Available at: http://www.macoalition.org/documents/RecMedPractices. pdf. Accessed July 27, 2005.

67. Whittington J, Cohen H. OSF healthcare's journey in patient safety. Qual Manag Health Care. 2004;13(1):53-59.

68. Kosecoff J, Kahn KL, Rogers WH, et al. Prospective payment system and impairment at discharge. The 'quicker-andsicker' story revisited. JAMA. 1990;264:1980-1983.

69. Reiley P, Iezzoni LI, Phillips R, Davis RB, Tuchin LI, Calkins D. Discharge planning: comparison of patients and nurses' perceptions of patients following hospital discharge. Image J Nurs Sch. 1996;28(2):143-147.

70. Coleman EA, Parry C, Chalmers S, Min S. The Care Transitions Intervention: results of a randomized controlled trial. Arch Intern Med. 2006;166:1822-1828.

71. Phillips CO, Wright SM, Kern DE, Singa RM, Shepperd S, Rubin HR. Comprehensive discharge planning with postdischarge support for older patients with congestive heart failure: a meta-analysis. JAMA. 2004;291:1358-1367.

72. Shepperd S, Parkes J, McClaran J, Phillips C. Discharge planning from hospital to home. Cochrane Database Syst Rev. 2006;4.

73. Coleman EA. Falling through the cracks: challenges and opportunities for improving transitional care for persons with continuous complex care needs. J Am Geriatr Soc. 2003;51:549-555.

74. Lowenthal G. The best way to improve emergency department follow-up is actually to give the patient a specific appointment. J Gen Intern Med. 2006;21:398; author reply 398.

75. van Walraven C, Mamdani M, Fang J, Austin PC. Continuity of care and patient outcomes after hospital discharge. J Gen Intern Med. 2004;19:624-631.

76. Makaryus AN, Friedman EA. Patients' understanding of their treatment plans and diagnosis at discharge. Mayo Clin Proc. 2005;80:991-994.

77. Dudas V, Bookwalter T, Kerr KM, Pantilat SZ. The impact of follow-up telephone calls to patients after hospitalization. Am J Med. 2001;111(9B):26S-30S.

78. Lipton HL, Bird JA. The impact of clinical pharmacists' consultations on geriatric patients' compliance and medical care use: a randomized controlled trial. Gerontologist. 1994;34:307-315.

79. Mistiaen P, Poot E. Telephone follow-up, initiated by a hospital-based health professional, for postdischarge problems in patients discharged from hospital to home. Cochrane Database Syst Rev. 2007;1.

80. Kravitz RL, Reuben DB, Davis JW, et al. Geriatric home assessment after hospital discharge. J Am Geriatr Soc. 1994; 42:1229-1234.

81. Stewart S, Pearson S. Uncovering a multitude of sins: medication management in the home post acute hospitalisation among the chronically ill. Aust N Z J Med. 1999;29(2): 220-227.

82. Naylor MD, Brooten D, Campbell R, et al. Comprehensive discharge planning and home follow-up of hospitalized elders: a randomized clinical trial. JAMA. 1999;281:613-620. 
83. Weinberger M, Smith DM, Katz BP, Moore PS. The costeffectiveness of intensive postdischarge care. A randomized trial. Med Care. 1988;26:1092-1102.

84. Bours GJ, Ketelaars CA, Frederiks CM, Abu-Saad HH, Wouters EF. The effects of aftercare on chronic patients and frail elderly patients when discharged from hospital: a systematic review. J Adv Nurs. 1998;27:1076-1086.

85. Rich MW, Beckham V, Wittenberg C, Leven CL, Freedland KE, Carney RM. A multidisciplinary intervention to prevent the readmission of elderly patients with congestive heart failure. N Engl J Med. 1995;333:1190-1195.

86. Alibhai SMH, Han RK, Naglie G. Medication education of acutely hospitalized older patients. J Gen Intern Med. 1999; 14:610-616.

87. Calkins DR, Davis RB, Reiley P, et al. Patient-physician communication at hospital discharge and patients' understanding of the postdischarge treatment plan. Arch Intern Med. 1997; 157:1026-1030.

88. Gibbs R, Gibbs P, Henrich J. Patient understanding of commonly used medical vocabulary. J Fam Pract. 1987;25:176-178.

89. Cole R. The understanding of medical terminology used in printed health education materials. Heal Educ J. 1979;38: 111-121.

90. Davis TC, Crouch MA, Wills G, Miller S, Abdehou DM. The gap between patient reading comprehension and the readability of patient education materials. J Fam Pract. 1990; 31:533-538.

91. Kutner M, Greenberg E, Baer J. National Assessment of Adult Literacy (NAAL). A first look at the literacy of America's adults in the 21st century. Available at: http://nces.ed.gov/naal. Accessed May 2, 2006.

92. Kirsh I, Jungeblut A, Jenkins L, Kolstad A. Adult Literacy in America: A First Look at the Findings of the National Adult Literacy Survey. Washington, DC: National Center for Education Statistics, U.S. Department of Education; 1993.

93. Williams MV, Davis TC, Parker RM, Weiss BD. The role of health literacy in patient-physician communication. Fam Med. 2002;34:383-389.

94. American Medical Association Council on Scientific Affairs. Health literacy. JAMA. 1999;281:552-557.

95. National Work Group on Literacy and Health. Communicating with patients who have limited literacy skills. J Fam Pract. 1998;46:168-176.
96. Weiss BD, Coyne C. Communicating with patients who cannot read. N Engl J Med. 1997;337:272-274.

97. DeWalt DA, Berkman ND, Sheridan S, Lohr KN, Pignone MP. Literacy and health outcomes: a systematic review of the literature. J Gen Intern Med. 2004;19:1129-1139.

98. Howard DH, Gazmararian J, Parker RM. The impact of low health literacy on the medical costs of Medicare managed care enrollees. Am J Med. 2005;118:371-377.

99. Baker DW, Parker RM, Williams MV, Clark WS. Health literacy and the risk of hospital admission. J Gen Intern Med. 1998;13:791-798.

100. John-Baptiste A, Naglie G, Tomlinson G, et al. The effect of English language proficiency on length of stay and inhospital mortality. J Gen Intern Med. 2004;19(3):221-228.

101. Louis-Simonet M, Kossovsky MP, Sarasin FP, et al. Effects of a structured patient-centered discharge interview on patients' knowledge about their medications. Am J Med. 2004;117:563-568.

102. Mahler HI, Kulik JA, Tarazi RY. Effects of a videotape information intervention at discharge on diet and exercise compliance after coronary artery bypass surgery. J Cardiopulm Rehab. 1999;19(3):170-177.

103. Flores $\mathrm{G}$. The impact of medical interpreter services on the quality of health care: a systematic review. Med Care Res Rev. 2005;62(3):255-299.

104. Katz MG, Kripalani S, Weiss BD. Use of pictorial aids in medication instructions: a review of the literature. $A m \mathrm{~J}$ Health Syst Pharm. 2006;63:2391-2397.

105. Houts PS, Doak CC, Doak LG, Loscalzo MJ. The role of pictures in improving health communication: A review of research on attention, comprehension, recall, and adherence. Patient Educ Couns. 2006;61(2):173-190.

106. Schillinger D, Piette J, Grumbach K, et al. Closing the loop. Physician communication with diabetic patients who have low health literacy. Arch Intern Med. 2003;163:83-90.

107. National Quality Forum. Safe Practices for Better Healthcare, 2003; Washington, DC.

108. Shojania KG, Duncan BW, McDonald KM, Wachter RM, eds. Making Healthcare Safer: A Critical Analysis of Patient Safety Practices. Evidence Report No. 43 from the Agency for Healthcare Research and Quality. AHRQ Publication No. 01-E058; 2001. 